\title{
Potential for a novel manganese porphyrin compound as adjuvant canine lymphoma therapy
}

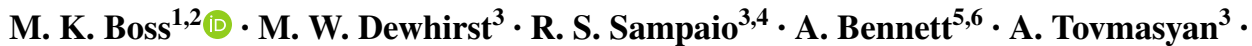 \\ K. G. Berman ${ }^{7}$ A. W. Beaven ${ }^{8}$ - D. A. Rizzieri ${ }^{8}$ - I. Batinic-Haberle ${ }^{3}$ M. L. Hauck ${ }^{5}$. \\ I. Spasojevic ${ }^{8,9}$
}

Received: 1 February 2017 / Accepted: 20 June 2017 / Published online: 6 July 2017

(C) The Author(s) 2017. This article is an open access publication

\begin{abstract}
Purpose Manganese porphyrins are redox-active drugs and superoxide dismutase mimics, which have been shown to chemosensitize lymphoma, a cancer which frequently occurs in dogs. This study aimed to identify critical information regarding the pharmacokinetics and toxicity of $\mathrm{Mn}(\mathrm{III})$ meso-tetrakis ( $N$-n-butoxyetylpyridium-2-yl) porphyrin, (MnTnBuOE-2-PyP $\left.{ }^{5+}, \mathrm{MnBuOE}\right)$ in dogs as a prelude to a clinical trial in canine lymphoma patients.

Methods A single-dose pharmacokinetic (PK) study in normal dogs was performed to determine the plasma halflife $\left(t_{1 / 2}\right)$ of MnBuOE. A dose reduction study was performed to establish the maximum tolerated dose (MTD) of MnBuOE. The safety and PK of a multi-dosing protocol was assessed.

Results Peak plasma drug concentration occurred $30 \mathrm{~min}$ post-injection. The $t_{1 / 2}$ was defined as $7 \mathrm{~h}$. MnBuOE
\end{abstract}

M. L. Hauck and I. Spasojevic senior authors contributed equally to this work.

Electronic supplementary material The online version of this article (doi:10.1007/s00280-017-3372-z) contains supplementary material, which is available to authorized users.

M. W. Dewhirst

mark.dewhirst@duke.edu

1 Department of Molecular Biomedical Sciences, North Carolina State University, Raleigh, NC 27607, USA

2 Department of Environmental and Radiological Health Sciences, Colorado State University, Fort Collins, CO 80523, USA

3 Department of Radiation Oncology, Duke University School of Medicine, Durham, NC 27710, USA

4 Departamento de Quimica, CCEN, Universidade Federal da Paraiba, Joao Pessoa, PB, Brazil induced an anaphylactic reaction and prolonged tachycardia. The MTD was defined as $0.25 \mathrm{mg} / \mathrm{kg}$. The dogs were given MTD 3 $\times /$ week for 2-3 weeks. The highest recorded tissue drug levels were in the lymph nodes $(4-6 \mu \mathrm{M})$, followed by kidney and liver $(2.5,2.0 \mathrm{uM}$, respectively).

Conclusions We obtained critical information regarding the PK and toxicity of $\mathrm{MnBuOE}$ in dogs. The acute drug reaction and tachycardia post-injection have not been described in other species and may be specific to canines. The high tissue drug levels in lymph nodes have not been previously reported. MnBuOE accumulation in lymph nodes has important implications for the utility of adjuvant $\mathrm{MnBuOE}$ to treat lymphoma. With MnBuOE lymph node accumulation, reduction in the dose and/or administration frequency could be possible, leading to reduced toxicity.

Keywords Manganese porphyrin - Canine · Lymph node $\cdot$ Lymphoma
5 Department of Clinical Sciences, North Carolina State University, Raleigh, NC 27607, USA

6 Las Vegas Veterinary Specialty Center, Las Vegas, NV 89147, USA

7 Bridge Pathology, Bristol, England, UK

8 Department of Medicine, Duke University School of Medicine, Durham, NC 27710, USA

9 Pharmaceutical Research Shared Resource, PK/PD Core Laboratory, Duke Cancer Institute, Durham, NC 27710, USA 


\section{Introduction}

Cancer therapy should operate with a wide therapeutic index whereby tumor cells are preferentially killed and normal tissues are protected. Unfortunately, the most common cancer treatments are toxic to both tumor and normal tissues and the therapeutic index is narrow. Many cancer therapeutics increase cellular oxidative stress and this stress can induce cell death. Increased oxidative stress has been observed after radiation therapy, several common chemotherapy agents, and even targeted agents [1-4]. While the increase in oxidative stress contributes to tumor cell cytotoxicity, it can also be damaging to normal tissues. We have designed a novel manganese porphyrin, MnTBuOE$2-\mathrm{PyP}^{5+}(\mathrm{MnBuOE})$ (Fig. 1). MnBuOE is a superoxide dismutase (SOD) mimic, which has been shown to sensitize tumor cells to chemotherapy and radiotherapy while protecting normal tissue by modulating tissue reduction-oxidation (redox) status [5-9]. Recently, we have reviewed the structure-activity relationships and impact of these manganese porphyrin therapeutics on cellular redox-based signaling pathways [10].

$\mathrm{MnBuOE}$ has divergent effects on tumor and normal tissue due to the inherent differences in basal cellular oxidative stress levels. Normal tissues have low levels of reactive species, and, in this context, MnBuOE serves
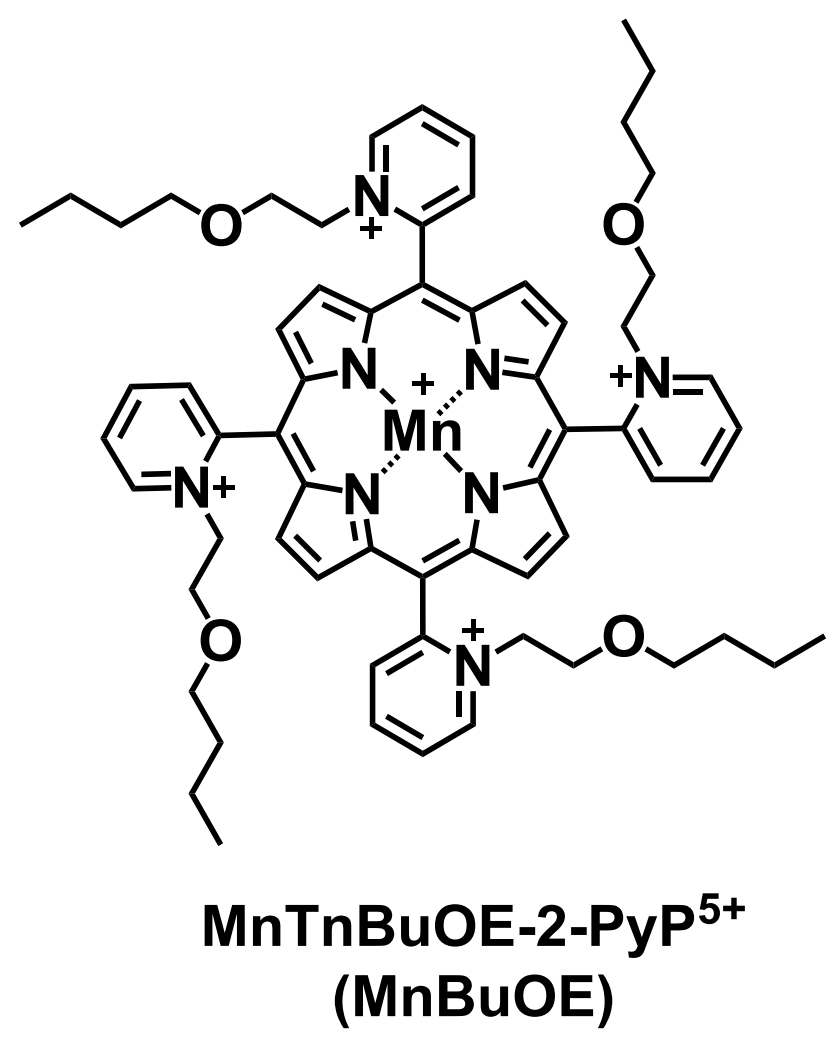

Fig. 1 Chemical structure of the studied compound as an antioxidant, marginally suppressing NF-kB activity, triggering anti-inflammatory responses, preventing cycling oxidative stress, and protecting normal cells from damage [10]. In tumors, however, an excessive baseline level of oxidative stress exists. The oxidative stress is driven by accumulation of the long-lasting reactive oxygen species, hydrogen peroxide. This excessive baseline level of oxidative stress is further enhanced by cancer therapies. As a cancer therapy adjuvant, $\mathrm{MnBuOE}$ serves as a pro-oxidant, stimulating the peroxide-induced oxidation of NF-kB, suppressing mitochondrial respiration, inhibiting glycolysis, and driving tumor cytotoxicity [10].

$\mathrm{MnBuOE}$ is primed for clinical use as an adjuvant cancer therapy and normal tissue protector. The compound has been optimized for pharmacodynamics with minimal toxicity and has entered Phase I/II Clinical Trials at Duke University as a radioprotector of normal tissue for patients with glioma who are treated with radiotherapy and temozolomide (Clinical Trial NCT02655601, clinicaltrials.gov).

A manganese porphyrin derivative from $\mathrm{MnBuOE}$, MnTE-2-PyP5+, has shown benefits as a chemosensitizer for lymphoma. Lymphoma is a hematologic malignancy which develops within the lymph nodes. Jaramillo et al. demonstrated that MnTE-2-PyP5+ enhanced the chemotherapeutic response of murine lymphoma cell lines and primary human lymphoma samples in vitro and ex vivo, respectively $[11,12]$. Chemosensitization of lymphoma cells by adjuvant manganese porphyrin would have significant implications for patients undergoing chemotherapy. As with many preclinical models, rodent models of lymphoma may not accurately portray the natural biology of the disease [13, 14]. Instead, important information regarding the clinical use of adjuvant $\mathrm{MnBuOE}$ in treating lymphoma may be gleaned from a comparative canine oncology trial [15].

Dogs develop a broad spectrum of naturally occurring cancers that share strong similarities with human cancers: they are an out-bred population, and, like human patients, pets receive state-of-the-art medical care; studying dogs with cancer offers a remarkable opportunity for preclinical modeling $[15,16]$. For the interest of this study, we are considering canine lymphoma and the potential to perform a comparative oncology clinical trial to investigate the utility of $\mathrm{MnBuOE}$ as an adjuvant to canine lymphoma therapy. Positive results from a canine lymphoma trial would provide support for moving $\mathrm{MnBuOE}$ into clinical trials as an adjuvant to human lymphoma therapy. Many similarities exist between human and canine lymphoma: both are spontaneously occurring and genetically diverse, most patients are diagnosed with the Non-Hodgkin's type of lymphoma, and they are both treated with CHOP-based chemotherapy treatment protocols. The clinical value in studying pet dogs with lymphoma as a model of the human disease is actively being researched and reported $[17,18]$. 
Before introducing $\mathrm{MnBuOE}$ into the veterinary clinic to perform a companion canine lymphoma clinical trial, the goal of this study was to determine the safety and optimal dosing regimen of $\mathrm{MnBuOE}$ in normal dogs.

\section{Materials and methods}

\section{Dogs}

All animal care and experimental procedures were approved by and complied with the regulations of the North Carolina State University Institutional Animal Care and Use Committee, as described in the Guide for Care and Use of Laboratory Animals published by the National Institutes of Health (NIH Publication No. 85-23, revised 1985). Three adult male Beagle dogs (4 years old; one reproductively intact, two neutered; weight: $11.6-13.1 \mathrm{~kg}$ ) were used for all phases of this study. Baseline physical examination and systemic health analysis with standard laboratory assessments (complete blood cell count, biochemistry panel, urinalysis) confirmed that the dogs were in good health prior to initiation of the study.

\section{MnBuOE structure and preparation}

The chemical structure of $\mathrm{MnBuOE}$ is shown in Fig. 1 . $\mathrm{MnBuOE}$ was synthesized and purified according to the procedures described elsewhere [19, 20].

\section{Monitoring}

Safety was assessed by evaluation of standard physical and laboratory parameters of systemic health. A full physical examination was performed prior to initiation of the study and on each treatment and sampling day. Indirect blood pressure monitoring was performed using Cardell Vet Monitor 9401 Blood Pressure Monitor. Pulse was quantified as heart beats per minute according to manual counts, as well as quantified with a blood pressure monitor. There was good correlation between pulse rates counted with manual methods compared to the blood pressure monitor (Figure S1). Standard laboratory assessments (complete blood cell count, biochemistry panel, urinalysis) were repeated throughout the phases of the study to assess systemic health.

\section{Initial dose for single-dose pharmacokinetic and MTD studies}

Prior toxicokinetic studies in mice and nonhuman primates in which $\mathrm{MnBuOE}$ was administered subcutaneously every 3 days for 5 weeks demonstrated no adverse effects level
(NOAEL) to be $12 \mathrm{mg} / \mathrm{kg}$ loading dose and $2 \mathrm{mg} / \mathrm{kg}$ maintenance dose in mice and $6 \mathrm{mg} / \mathrm{kg}$ loading dose and $2 \mathrm{mg} /$ $\mathrm{kg}$ maintenance dose in nonhuman primates [21]. Pharmacodynamic studies in mice demonstrated that a dose of $1 \mathrm{mg} / \mathrm{kg}$ is adequate to achieve pharmacologically active levels in normal and tumor tissues [5, 6, 10, 22, 23]. Thus, $1 \mathrm{mg} / \mathrm{kg}$ was selected as a safe initial dose for the MTD and single-dose PK studies in this work.

\section{Single-dose pharmacokinetic study}

Intravenous catheters were placed in the jugular vein of each dog under heavy sedation (dexmedetomidine, $500 \mathrm{mcg} / \mathrm{m}^{2}$ ) 24-h prior to initiation of the pharmacokinetic study to facilitate blood sampling. Baseline pulse and blood pressure (Cardell Vet Monitor 9401 Blood Pressure Monitor) were recorded prior administration of $\mathrm{MnBuOE}$. $\mathrm{MnBuOE}(5.64 \mathrm{mg} / \mathrm{mL})$ was injected subcutaneously in the dorsal intrascapular region. Following injection, 3-6 mL of blood was collected after $10 \mathrm{~min}, 30 \mathrm{~min}, 1 \mathrm{~h}, 2 \mathrm{~h}, 4 \mathrm{~h}$, $6 \mathrm{~h}, 8$ h, 24 h, 48 h, 72 h, 7 days, and 14 days into lithium heparin tubes (Vacutainer, $1.3 \mathrm{~mL}$ ). Whole blood was centrifuged at $1500 \times g$ for $20 \mathrm{~min}$, and plasma was collected and stored in $1 \%$ citric acid at $-80{ }^{\circ} \mathrm{C}$.

\section{Defining maximally tolerated dose}

The maximally tolerated dose (MTD) to be used as an initial (loading) dose for the multiple dose pharmacokinetic study was defined as the dose of MnBuOE which did not induce clinically intolerable side effects in the dogs.

\section{Multiple dose pharmacokinetic study}

The dosing regimen selected for the multiple dose pharmacokinetic study was based on the $t_{1 / 2}$ defined in the single dose pharmacokinetic study. Blood samples were collected prior to and $1 \mathrm{~h}$ following administration of $\mathrm{MnBuOE}$. Blood samples were processed and stored as described for the single-dose pharmacokinetic study. Pulse was counted manually prior to and $1 \mathrm{~h}$ following administration of MnBuOE. This multiple dose pharmacokinetic study was performed twice to ensure plasma drug levels were maintained as predicted and that these results were reproducible. The first study involved a treatment period of 3 weeks, and the second study spanned a treatment period of 2 weeks leading up to euthanasia with necropsy and tissue harvest.

Samples from organs and tissues of interest were harvested during necropsy and placed over dry ice until stored at $-80{ }^{\circ} \mathrm{C}$. Drug concentration was analyzed by LC/ MS-MS. 


\section{Histopathologic evaluation}

Tissue samples collected at necropsy were stored in $10 \%$ neutral buffered formalin, paraffin embedded, sectioned, and stained with hematoxylin and eosin. Histopathologic evaluations of the tissues were performed by a veterinary pathologist (KGB).

\section{Measurement of MnBuOE in plasma and organs}

\section{Plasma and tissue processing}

Organs were cryo-pulverized in a Bessman tissue pulverizer (BioSpec Products, Bartlesville, OK) under liquid nitrogen and then homogenized in a rotary homogenizer (PTFE pestle and glass tube) with two volumes of deionized water. An aliquot of either plasma or tissue homogenate was transferred into a 2-mL polypropylene screw-cap vial and a double volume of $1 \% \mathrm{HCl}$ in methanol was added, agitated in FastPrep apparatus (Q-biogene, Carlsbad, CA) at speed 6.5 for $20 \mathrm{~s}$, and centrifuged $10 \mathrm{~min}$ at 16,000g. For plasma an aliquot of the supernatant was pipetted into a HPLC autosampler polypropylene vial and $80 \mu \mathrm{L}$ of $0.1 \%$ heptafluorobutyric acid (HFBA) in water was added. It was followed by another cycle of centrifugation for $5 \mathrm{~min}$ at $4500 \mathrm{~g}\left(4^{\circ} \mathrm{C}\right)$, after which the sample was immediately analyzed by LC-MS/MS. For other organs, an aliquot of the supernatant was pipetted into a $5-\mathrm{mL}$ polypropylene tube $(10 \times 50 \mathrm{~mm})$ and the solvent was completely removed in a Savant Speed-Vac evaporator at $40{ }^{\circ} \mathrm{C}$ within $1 \mathrm{~h}$. The dry residue was dissolved in $20 \mu \mathrm{L}$ of mobile phase B (see below) and sonicated for $5 \mathrm{~min}$; then $80 \mu \mathrm{L}$ of mobile phase B was added, the mixture was sonicated again for $5 \mathrm{~min}$, and centrifuged for $5 \mathrm{~min}$ at $4500 \mathrm{~g}$ at $4{ }^{\circ} \mathrm{C}$. Finally, the tube content was transferred to the HPLC autosampler polypropylene vial equipped with silicone/polytetrafluoroethylene septum, followed by another cycle of centrifugation for $5 \mathrm{~min}$ at $4500 \mathrm{~g}\left(4^{\circ} \mathrm{C}\right)$, placed in autosampler $4{ }^{\circ} \mathrm{C}$, and analyzed by LC-MS/MS.

\section{Liquid chromatography-tandem mass spectroscopy (LC-MS/MS)}

Quantitative analysis of MnBuOE was performed on a Shimadzu 20A series HPLC (LC)—Applied Biosystems MDS Sciex 5500 QTrap tandem mass spectrometer (MS/MS) at PK/PD Core Laboratory of Duke Cancer Institute. The use of HFBA as an ion-pairing agent increases overall lipophilicity/volatility and greatly improves retention and ionization efficiency of the analytes, affording an abundance of $\left[\mathrm{MnP}^{5+}+2 \mathrm{HFBA}^{-}\right]^{3+}$ and $\left[\mathrm{MnP}^{5+}+3 \mathrm{HFBA}^{-}\right]^{2+}$ ions. Solvents employed were: $A=9: 1$ water:acetonitrile $(0.05 \%$ HFBA); $B=$ acetonitrile ( $0.05 \%$ HFBA). Analytical column:
$2 \times$ Phenomenex AJ0-4287, C18, $4 \times 3 \mathrm{~mm}$ at room temperature. Elution gradient: $0-1 \mathrm{~min} 0-70 \% \mathrm{~B}, 1-2 \min 70 \% \mathrm{~B}$, 2-2.1 min $70-100 \% \mathrm{~B}, 2.1-2.6 \mathrm{~min} 100 \% \mathrm{~B}, 2.6-2.7 \mathrm{~min}$ $100-0 \% B$. Run time: 4 min. Mass transitions used for quantification: MnTnBuOE-2-PyP ${ }^{5+}$ at $m / z=857.3 / 599$ and MnTnBuOE-2-PyP ${ }^{5+}-\mathrm{d}_{8}$ (internal standard) at $m / z=862.2 / 603.9$. Calibration samples in $1-1000 \mathrm{nM}$ or $0.1-10 \mu \mathrm{M}$ range (depending on the expected levels) were prepared by adding known amounts of serially diluted pure standards into plasma or corresponding tissue homogenates and were analyzed along with study samples. Response was calculated as the ratio between the standard peak area and internal standard peak area.

\section{Results}

\section{Single-dose pharmacokinetic study}

The complex PK profile obtained is presented in Fig. 2a, b. Relevant PK parameters (e.g. $C_{\max }, T_{\max }$, AUC, clearance, $t_{1 / 2}$ ) were obtained by compartmental and non-compartmental modules within WinNonlin v. 2.1 software (Pharsight Corp. Cary NC) and are presented in Table 1. Plasma $\mathrm{MnBuOE}$ levels peaked at $30 \mathrm{~min}$ post-injection with a mean concentration of $3.993 \mu \mathrm{M}$ (Fig. 2a), followed by a complex tissue distribution profile (non-linear trace in loglinear plot) within first $6 \mathrm{~h}$ post injection (Fig. 2a). From 6 to $48 \mathrm{~h}$, however, a single exponential (linear in log-linear plot, Fig. 2b) elimination process from the central compartment (e.g. plasma and weakly bound drug to plasma proteins, membranes, etc) was observed with the half-life $t_{1 / 2}=7 \mathrm{~h}$, leaving only $1 \%$ of $\mathrm{MnBuOE}$ remaining in plasma. From $48 \mathrm{~h}$ to 14 days (Fig. 2b), a complex process (presumably a slow elimination from "deep" compartments) was observed with the estimated "terminal" half-life of 20 days. Selected PK parameters from compartmental and non-compartmental PK calculations are presented in Table 1. Compartmental (first-order absorption-2 compartment model) calculations including $0-48 \mathrm{~h}$ data were performed on the averaged PK profile for the purpose of obtaining PK parameters needed for the simulation of the multi-dose regimen.

\section{Defining maximally tolerated dose}

\section{Results at $1 \mathrm{mg} / \mathrm{kg}$}

Administration of the $1 \mathrm{mg} / \mathrm{kg}$ dose resulted in unexpected and unacceptable toxicities in all of the dogs. The first toxicity was an acute anaphylactic drug reaction which developed 15-20 min following injection of MnBuOE. This reaction was characterized by hyperemic mucus membranes, head shaking, urticaria, restlessness, and protrusion of the third eyelids. These clinical signs were resolved 


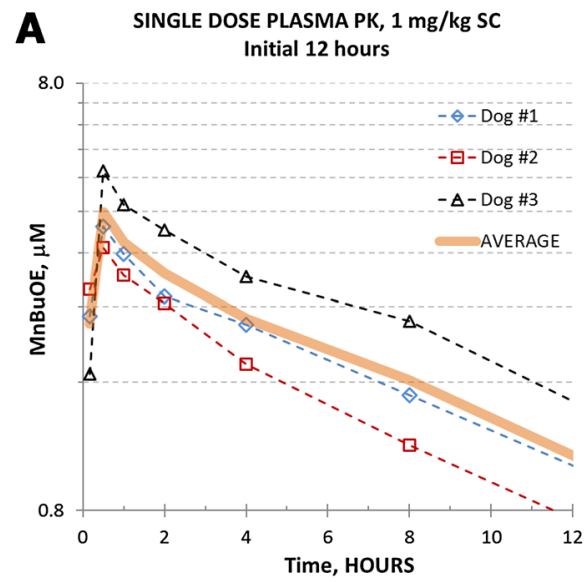

Fig. 2 Pharmacokinetic profile of $\mathrm{MnBuOE}$ in dog after single subcutaneous injection. a Concentration of $\mathrm{MnBuOE}$ in plasma during initial $12 \mathrm{~h}$ after single subcutaneous injection of $1 \mathrm{mg} / \mathrm{kg}$ (in 100 $\mu \mathrm{L}$ saline) to 3 dogs (average line presented for vizualization only). Absorption from subcutaneous space $\left(T_{\max }=30 \mathrm{~min}\right)$ is followed by

Table 1 PK parameters

\begin{tabular}{|c|c|c|c|c|}
\hline \multirow{2}{*}{$\begin{array}{l}\text { Win nonlin PK calculation } \\
\text { PK parameter }\end{array}$} & \multicolumn{2}{|c|}{$\begin{array}{l}\text { Non-compart- } \\
\text { mental }\end{array}$} & \multicolumn{2}{|c|}{$\begin{array}{l}\text { First order } \\
\text { absorption two } \\
\text { compartments }\end{array}$} \\
\hline & Value & Std. error & Value & Std. error \\
\hline$t_{\max }(\mathrm{h})$ & 0.5 & 0 & 0.46 & 0.46 \\
\hline$C_{\max }(\mathrm{mg} / \mathrm{mL})$ & 5.00 & 0.64 & 4.83 & 0.21 \\
\hline $\mathrm{AUC}_{0-48 \mathrm{~h}}$ & 52.09 & 7.89 & N/A & N/A \\
\hline $\mathrm{AUC}_{\text {infinite }}$ & 57.82 & 7.65 & 42.52 & 19.24 \\
\hline$t_{1 / 2}(4-48 \mathrm{~h})(\mathrm{h})$ & 7.13 & 0.13 & 6.64 & 4.24 \\
\hline$t_{1 / 2}(7-14$ day) (day) & 21.24 & 2.11 & N/A & N/A \\
\hline $\begin{array}{l}\mathrm{V} / \mathrm{F}(4-48 \mathrm{~h} \text { process })(\mathrm{L} / \mathrm{kg} \\
\text { body weight })\end{array}$ & 0.21 & 0.03 & 0.14 & 0.76 \\
\hline $\begin{array}{l}\mathrm{V} / \mathrm{F} \text { ( } 7-14 \text { day process) }(\mathrm{L} / \mathrm{kg} \\
\text { body weight) }\end{array}$ & 13.42 & 2.92 & N/A & N/A \\
\hline $\mathrm{CL} / \mathrm{F}(\mathrm{L} / \mathrm{h} / \mathrm{kg}$ body weight $)$ & 0.020 & 0.003 & 0.02 & 0.01 \\
\hline
\end{tabular}

Non-compartmental parameter estimation module within WinNonlin software was performed on concentration/time sets from individual dogs after single $1 \mathrm{mg} / \mathrm{kg}$ dose to obtain critical PK parameters. Compartmental modeling (absorption +2 compartments) using average single-dose profile was performed to estimate the PK parameters in order to simulate the multi-dose regimen. Since the $4-48 \mathrm{~h}$ process dominates, selected PK parameters are in very good agreement; complexity of the overall profile and scarcity of the early data preclude rigorous compartmental modeling of all the processes observed

with treatment with an antihistamine medication (diphenhydramine, $2 \mathrm{mg} / \mathrm{kg}$ ). The second toxicity was a severe sinus tachycardia, which peaked $1 \mathrm{~h}$ after MnBuOE injection. Average heart rates at this time point were 210 beats per minute (Fig. 3a). By comparison, resting heart rate for these dogs averaged 88 beats per minute. This tachycardia persisted for at least $6 \mathrm{~h}$ (Fig. 3a), and pulses remained

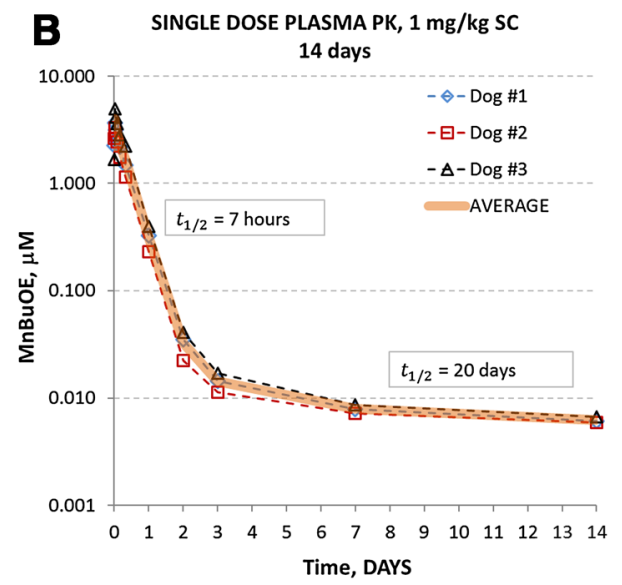

a complex distribution into various organs/compartments. b A single (linear in log-lin plot) plasma elimination process, leaving only $1 \%$ drug remaining, starts after first $8 \mathrm{~h}$ and ends in 2 days, followed by a complex elimination profile, presumably from cellular compartments of various affinity for the drug, extending beyond 2 weeks

increased compared to resting heart rates $24 \mathrm{~h}$ later (Fig. 3b). The tachycardia was not associated with changes in blood pressure (Figure S2), nor was the tachycardia alleviated by the antihistamine medication (diphenhydramine) or intravenous fluid therapy (Figure S3).

Local drug reactions in the subcutaneous site of injection occurred with two of the dogs. One dog developed non-painful, mild hyperemia the time of injection, and this resolved without treatment $48 \mathrm{~h}$ later. The other dog developed a non-painful, subcutaneous thickening 3 days after $\mathrm{MnBuOE}$ injection; this reaction resolved without treatment 4 days later. Alkaline urine $(\mathrm{pH}=9)$ was documented in two of the three dogs at $48 \mathrm{~h}$ after MnBuOE administration (Table 2).

\section{Results at $0.5 \mathrm{mg} / \mathrm{kg}$}

The dose of $\mathrm{MnBuOE}$ was reduced to $0.5 \mathrm{mg} / \mathrm{kg}$ and tested in one dog. MnBuOE was injected $1 \mathrm{~h}$ after pre-administration of diphenhydramine $(2 \mathrm{mg} / \mathrm{kg})$, famotidine $(0.5 \mathrm{mg} /$ $\mathrm{kg}$ ), and prednisone $(1 \mathrm{mg} / \mathrm{kg})$. The anaphylactic reaction seen with $\mathrm{MnBuOE}$ alone did not occur with pretreatment with these drugs. Based on this observation, the remainder of the studies reported in this paper included pre-medication with anti-histamines and steroids. No local drug reaction at the injection site was noted. However, the dog still developed a moderate tachycardia following administration of the $0.5 \mathrm{mg} / \mathrm{kg}$ dose, peaking at $1 \mathrm{~h}$ after injection with an average of 144 beats per minute; the heart rate $24 \mathrm{~h}$ later remained slightly increased (Fig. 3a, b). This degree of tachycardia was deemed too high to justify using this drug at this dose in a companion canine lymphoma clinical trial. 


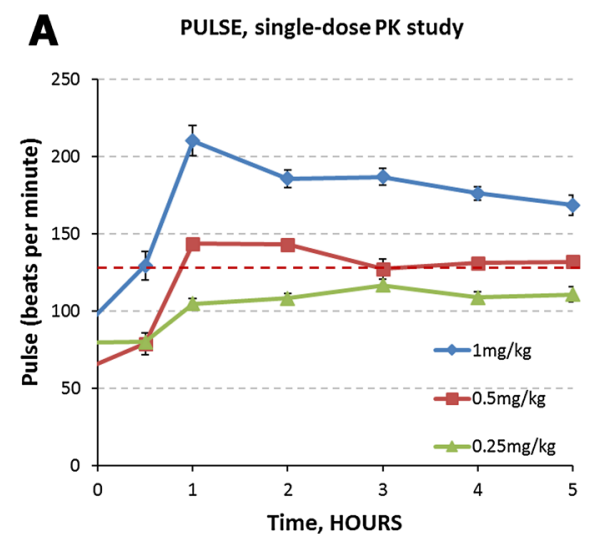

Fig. 3 Pulse measured after single MnBuOE injection. a Subcutaneous administration of $\mathrm{MnBuOE}$ induced a dose-responsive acute and persistent increase pulse rate $(n=3 / 3)$. A severe tachycardia was documented following administration with $1 \mathrm{mg} / \mathrm{kg} \mathrm{MnBuOE}$. Reducing the $\mathrm{MnBuOE}$ dose to $0.5 \mathrm{mg} / \mathrm{kg}$ resulted in a mild to moderate tachycardia. Reducing the dose to $0.25 \mathrm{mg} / \mathrm{kg} \mathrm{MnBuOE}$ increased

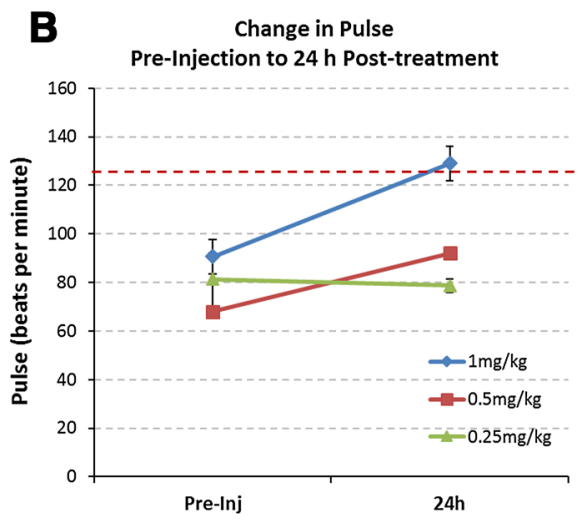

the pulse rate but did not induce a clinical tachycardia. Dotted line indicates the defined acceptable resting pulse rate for the dogs. $\mathbf{b}$ Subcutaneous administration of $\mathrm{MnBuOE}$ induced a dose-responsive increase in pulse rate that persisted $24 \mathrm{~h}$ post-injection. Treatment with $0.25 \mathrm{mg} / \mathrm{kg} \mathrm{MnBuOE}$ did not alter pulse rate $24 \mathrm{~h}$ post-injection

Table 2 Health assessments

\begin{tabular}{|c|c|c|c|c|c|c|}
\hline Laboratory test & Pre-treatment & $48 \mathrm{~h}$ post $1 \mathrm{mg} / \mathrm{kg}$ & \multicolumn{2}{|c|}{$48 \mathrm{~h}$ post $0.25 \mathrm{mg} / \mathrm{kg}$} & \multicolumn{2}{|l|}{3 weeks post $0.25 \mathrm{mg} / \mathrm{kg}$} \\
\hline \multicolumn{7}{|l|}{ Laboratory health assessments } \\
\hline Complete blood cell count & Unremarkable & Unremarkable & \multicolumn{2}{|c|}{ Unremarkable } & \multicolumn{2}{|c|}{$\begin{array}{l}\text { Stress leukogram (exogenous gluco- } \\
\text { corticoids) }(n=3 / 3)\end{array}$} \\
\hline Chemistry panel & Unremarkable & Unremarkable & \multicolumn{2}{|c|}{ Unremarkable } & \multicolumn{2}{|c|}{$\begin{array}{l}\text { Mild hypocholesterolemia }(n=3 / 3) \\
\text { Mildly increased liver enzyme } \\
\text { activity (ALP, ALT) }(n=3 / 3) \\
\text { Slight to mild metabolic acidosis } \\
\text { (increased anion gap) }(n=3 / 3)\end{array}$} \\
\hline Urinalysis & Unremarkable & $\begin{array}{l}\text { Alkaline urine }(\mathrm{pH}=9) \\
(n=2 / 3)\end{array}$ & \multicolumn{2}{|c|}{$\begin{array}{l}\text { Alkaline urine }(\mathrm{pH}=9) \\
(n=1 / 1)\end{array}$} & \multicolumn{2}{|c|}{ Alkaline urine $(\mathrm{pH}=9)(n=2 / 3)$} \\
\hline Affected organ/tissue & Diagnosis & & Incidence & Characterist & & Incidence \\
\hline \multicolumn{7}{|l|}{ Histopathologic evaluation } \\
\hline Lung & \multicolumn{2}{|c|}{ Bronchointerstitial/interstitial pneumonia } & $n=3 / 3$ & \multicolumn{2}{|c|}{$\begin{array}{l}\text { Multifocal, mild, neutrophilic, sterile } \\
\text { Multifocal, moderate, neutrophilic } \\
\text { sterile }\end{array}$} & $\begin{array}{l}n=2 / 3 \\
n=1 / 3\end{array}$ \\
\hline Liver & \multicolumn{2}{|c|}{ Hydropic degeneration } & $n=3 / 3$ & \multicolumn{2}{|c|}{$\begin{array}{l}\text { Marked, multifocal to diffuse, random } \\
\text { Marked, multifocal to diffuse, centri- } \\
\text { lobular to random } \\
\text { Marked, diffuse, panlobular, random }\end{array}$} & $\begin{array}{l}n=1 / 3 \\
n=1 / 3 \\
n=1 / 3\end{array}$ \\
\hline Kidney & \multicolumn{2}{|c|}{ Tubular degeneration and necrosis } & $n=3 / 3$ & \multicolumn{2}{|c|}{$\begin{array}{l}\text { Acute, multifocal, mild } \\
\text { Acute multifocal, moderate }\end{array}$} & $\begin{array}{l}n=2 / 3 \\
n=1 / 3\end{array}$ \\
\hline Subcutaneous adipose & Necrosuppu & granulomatous steatitis & $n=3 / 3$ & \multicolumn{2}{|c|}{ Multifocal, mild } & $n=3 / 3$ \\
\hline
\end{tabular}

$\mathrm{MnBuOE}$ at $0.25 \mathrm{mg} / \mathrm{kg}$ and concurrent oral medications. Slight to mild metabolic acidosis $(n=3 / 3)$ was also seen following this multiple dosing protocol. Single doses of $\mathrm{MnBuOE}(1,0.25 \mathrm{mg} / \mathrm{kg}$ ) and multiple doses of $\mathrm{MnBuOE}$ at $0.25 \mathrm{mg} / \mathrm{kg}$ did not alter blood cell volumes. Three weeks of treatment with prednisone induced shifts in white blood cell counts in a pattern consistent with administration of exogenous glucocorticoids. Tissue samples were stored in $10 \%$ neutral buffered formalin, paraffin embedded, sectioned, and stained with hematoxylin and eosin. Histopathologic evaluations of the tissues were performed by a veterinary pathologist $(\mathrm{KB})$. Varying degrees of bronchointerstitial/interstitial pneumonia $(n=3 / 3)$, hydropic degeneration of the liver $(n=3 / 3)$, tubular degeneration and necrosis of the kidney $(n=3 / 3)$, and necrosuppurative/granulomatous steatitis in the subcutaneous adipose tissue of the injection site $(n=3 / 3)$ were identified 
Results at $0.25 \mathrm{mg} / \mathrm{kg}$

No anaphylactic or local drug reactions were observed in the first dog treated with $0.25 \mathrm{mg} / \mathrm{kg}$, so this dose was repeated in the other two dogs. A mild increase in heart rate developed (range 104-116 beats per minute) following injection, but had normalized by $24 \mathrm{~h}$ (Fig. 3a, b). This level of increase in heart rate was considered clinically acceptable for a canine lymphoma trial. Laboratory health assessments were repeated $48 \mathrm{~h}$ following administration of $0.25 \mathrm{mg} / \mathrm{kg} \mathrm{MnBuOE}$. No remarkable changes in serum biochemistries were seen. Alkaline urine $(\mathrm{pH}=$ 9) was seen in the one dog from which urine was analyzed (Table 2). Based on these findings, $0.25 \mathrm{mg} / \mathrm{kg}$ of $\mathrm{MnBuOE}$ was defined as the MTD.

\section{Multiple dose pharmacokinetic studies}

$\mathrm{MnBuOE}$ was administered at $0.25 \mathrm{mg} / \mathrm{kg}$ Monday, Wednesday, and Friday (MWF). Dogs were treated concurrently with diphenhydramine $(2 \mathrm{mg} / \mathrm{kg}$ every $12 \mathrm{~h})$, famotidine $(0.5 \mathrm{mg} / \mathrm{kg}$ every $12 \mathrm{~h})$, and prednisone $(1 \mathrm{mg} /$ $\mathrm{kg}$ every $12 \mathrm{~h}$ ) throughout these studies. Blood/plasma was collected at two time points: $1 \mathrm{~h}$ post dose (expected high levels but "safely" away the peak at $C_{\max }=0.5 \mathrm{~h}$ ) and just prior to injection (trough level). The results are presented on Fig. 4a. As expected, the trough levels measured were very low. An important finding is that no accumulation of the drug in plasma was observed during the entire long-term treatment, i.e. high levels never exceeded the value observed after the first injection (based on which the MTD- $0.25 \mathrm{mg} / \mathrm{kg}$ was established). This would imply that no change in the expected mild acute side effects should be observed. Mildly to moderately increased heart rate $1 \mathrm{~h}$ after each injection was observed (Fig. 4b). The change in pulse increased over time for both treatment week and day of the week. Baseline pulse prior to injection was not altered with multiple doses of $\mathrm{MnBuOE}$.

\section{First study}

Laboratory health assessments were repeated on the final day of the initial 3-week study. Mildly increased liver enzyme activity (mean ALP 203 IU/L, reference range 16-140 IU/L; mean ALT $133 \mathrm{IU} / \mathrm{L}$, reference range 12-54 IU/L) and mild hypocholesterolemia (mean $96 \mathrm{mg} /$ $\mathrm{dL}$, reference range $124-344 \mathrm{mg} / \mathrm{dL}$ ) were documented in all three dogs, as well as a slight-to-mild anion gap metabolic acidosis (mean 21.5, reference range 11.2-19.9) (Table 2). Alkaline urine $(\mathrm{pH}=9)$ was reported for two of the three dogs. Prolonged treatment with prednisone induced shifts in white blood cell counts in a pattern consistent with administration of exogenous glucocorticoids $(n=3 / 3)$. One of the dogs developed a urinary tract infection and was successfully treated with enrofloxacin $(10 \mathrm{mg} /$ $\mathrm{kg}$ every $24 \mathrm{~h}$ for 10 days).

\section{Second study}

Following a 44-day wash-out period, the dogs were treated with the MWF protocol, beginning on a Monday, for a total of five doses of MnBuOE. Forty-eight hours after the last dose of $\mathrm{MnBuOE}$, the dogs were euthanized (intravenous injections of acepromazine $(0.2 \mathrm{mg} /$ $\mathrm{kg})$, butorphanol $(2.0 \mathrm{mg} / \mathrm{kg})$, and pentobarbital sodium $(390 \mathrm{mg} / \mathrm{mL} ; 1 \mathrm{~mL} / \mathrm{lb})$ and tissues were harvested.

\section{Histopathologic evaluation}

Varying degrees of bronchointerstitial/interstitial pneumonia $(n=3 / 3)$, hydropic degeneration of the liver $(n=$ $3 / 3)$, tubular degeneration and necrosis of the kidney $(n=$ $3 / 3$ ), and necrosuppurative/granulomatous steatitis in the subcutaneous adipose tissue of the injection site $(n=3 / 3)$ were identified (Table 2). Lymph nodes appeared mildly reactive, but this was not considered clinically significant.

\section{Tissue drug levels}

The highest recorded tissue drug levels were in the lymph nodes $(3.98-5.99 \mu \mathrm{M})$, followed by the kidney and liver (2.58, $1.97 \mu \mathrm{M}$, respectively) (Fig. 4c).

\section{Discussion}

In this study, we obtained critical information regarding the $\mathrm{PK}$ and toxicity of $\mathrm{MnBuOE}$ in normal dogs as a prelude to a planned clinical trial in canine patients with lymphoma.

The $t_{1 / 2}$ of $\mathrm{MnBuOE}$ was defined as $7 \mathrm{~h}$ via primary elimination and 20 days via secondary processes. Following a multi-dose PK study, the highest recorded tissue drug levels were in the peripheral lymph nodes $(3.98-5.99 \mu \mathrm{M})$, followed by the kidney and liver $(2.58,1.97 \mu \mathrm{M}$, respectively).

The most important result from the single-dose 14-day PK study was that the $99 \%$ of drug was eliminated from the plasma after $48 \mathrm{~h}$. This implies that, in a multi-dose treatment protocol, the same initial dose may be given every 2 days without the danger of drug accumulation above the established single-dose MTD. The data obtained from $48 \mathrm{~h}$ to 14 days suggest a slow elimination from multiple "deep" compartments (cell cytosol and organelles). Another important result is that $C_{\max }(4 \mu \mathrm{M})$ obtained in this study with dogs is much higher than the value observed in mice $\left[C_{\max } \sim 0.3 \mu \mathrm{M}\right.$ (dose adjusted from $6 \mathrm{mg} / \mathrm{kg}$ 


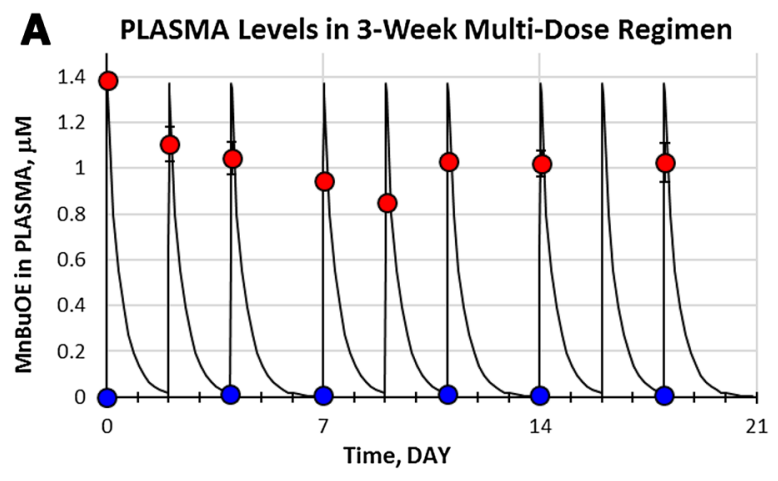

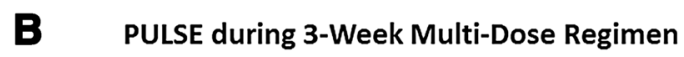

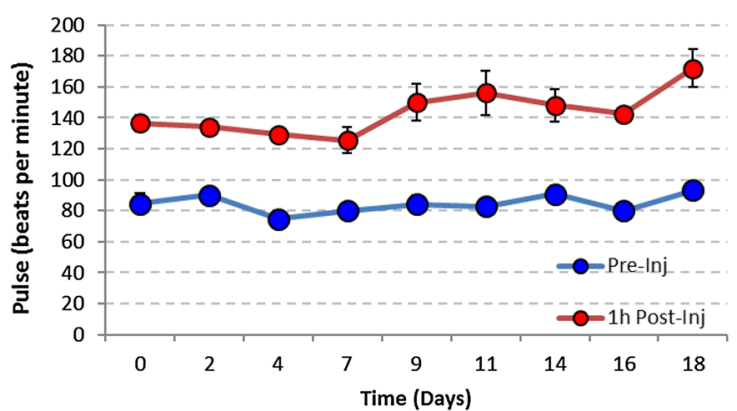

C

TISSUE Levels after 2-Week Multi-Dose Regimen

$0.25 \mathrm{mg} / \mathrm{kg} 3 \times$ per week via SC

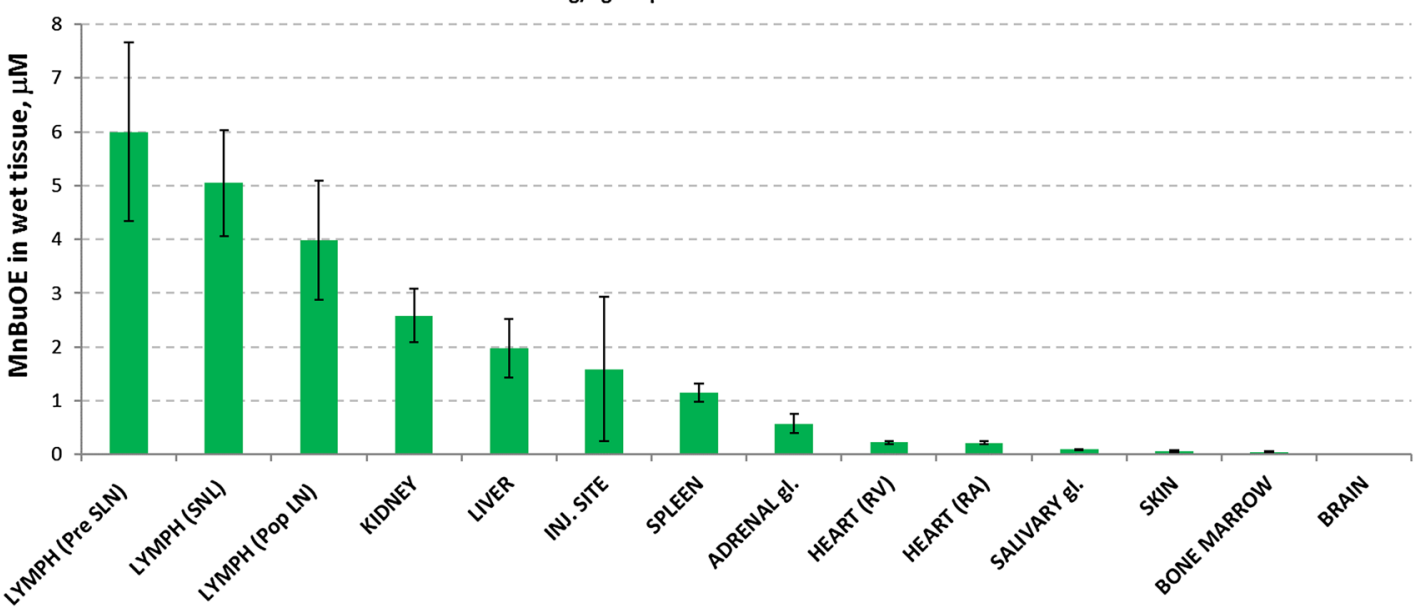

Fig. 4 Tissues after 2-week multi-dose subcutaneous treatment. a $\mathrm{MnBuOE}$ was administered subcutaneously at $0.25 \mathrm{mg} / \mathrm{kg}$ every Monday, Wednesday, and Friday for 3 weeks. Plasma MnBuOE was measured pre-injection and $1 \mathrm{~h}$ post-injection. MnBuOE concentration was highest following the initial dose $(1.4 \mu \mathrm{M})$ then plateaued with subsequent doses with a range of approximately 0.85 to $1.1 \mu \mathrm{M}$. Owing to $7 \mathrm{~h}$ half-life of the elimination and even shorter initial distribution-phase half-life, $\mathrm{MnBuOE}$ was essentially cleared prior to each subsequent dose; consequently, no plasma accumulation was observed. b Subcutaneous administration of $\mathrm{MnBuOE}$ at $0.25 \mathrm{mg} / \mathrm{kg}$ increased pulse rate $1 \mathrm{~h}$ post-injection. When MnBuOE was admin-

[21]) and $C_{\max }=1 \mu \mathrm{M}(1 \mathrm{mg} / \mathrm{kg}$, unpublished data)], rats $\left[C_{\max }=1 \mu \mathrm{M}(1 \mathrm{mg} / \mathrm{kg}\right.$, unpublished data $\left.)\right]$, and nonhuman primates $\left[C_{\max }=1.6 \mu \mathrm{M}(1 \mathrm{mg} / \mathrm{kg}\right.$ [21])]. This can explain the unexpected serious side effects and the lower than expected MTD established in this study with dogs.

Based on the results from the multiple-dose PK study, it was confirmed that the plasma peak concentration is controlled (no accumulation observed over time, Fig. 4a). This suggests that the acute toxicity signs should not worsen over the course of long-term therapy. Tissue analysis revealed accumulation of the drug within organs. Particularly encouraging for this study is that the highest tissue drug levels were observed in lymph nodes. If plasma peak concentration were the only controlling factor for the istered Mon/Wed/Fri for 3 weeks, the change in pulse increased over time for both treatment week and day of the week. Pre-injection pulse rate was not altered with multiple dosing of MnBuOE. c Dogs received $0.25 \mathrm{mg} / \mathrm{kg} \mathrm{MnBuOE} \mathrm{Mon/Wed/Fri} \mathrm{for} \mathrm{a} \mathrm{total} \mathrm{of} \mathrm{five} \mathrm{doses}$ prior to euthanasia. Tissues were harvested $48 \mathrm{~h}$ post-last injection. Even after $48 \mathrm{~h}$, most tissues retained higher concentration of the drug than the $C_{\max }$ in plasma, suggesting that the drug accumulates during the given dosing regimen. Drug levels were highest in peripheral lymph nodes (prescapular, submandibular, popliteal) and lowest in brain tissue

acute toxicity, the observed tissue accumulation would be only beneficial for the treatment. However, pulse data as well as laboratory assessments suggest that controlling plasma level is not sufficient and that long-term multipledose MTD should be lower than $0.25 \mathrm{mg} / \mathrm{kg}$ and/or frequency of dosing extended to once-weekly, depending on the application.

As we prepare to move toward testing the utility of adjuvant $\mathrm{MnBuOE}$ in the treatment of naturally occurring canine lymphoma, the finding that the highest drug levels were measured in the lymph nodes is particularly encouraging. The high tissue drug levels in lymph nodes have not been documented previously; this was the first animal study to perform such measurements. Although it is 
a different cell type, we have reported a threefold higher accumulation of manganese porphryins in the nucleus of macrophages compared to the cytosol [24]. It is likely that $\mathrm{MnBuOE}$ is also accumulating in the nucleus of lymphocytes. Lymphocytes are a cell type with a very high nuclear to cytosolic ratio and they are tightly packed with a high cell density within the parenchyma of lymph nodes [25]. The preferential accumulation of $\mathrm{MnBuOE}$ in lymph nodes is likely due to both the accumulation of the drug within the nucleus of lymphocytes and the high lymphocyte cell density in the lymph node. Although MnBuOE lymph node accumulation was recorded in normal, healthy dogs in this study, it is important to consider that manganese porphyrin compounds also accumulate in tumor tissue. Recently, we demonstrated that MnTE2-PyP5+, a manganese porphyrin compound similar to $\mathrm{MnBuOE}$, accumulates preferentially in tumor tissue compared to normal tissue [22]. Evidence that manganese porphyrin compounds accumulate in both primary tumor tissue and lymph nodes strengthens the justification to use $\mathrm{MnBuOE}$ in a canine lymphoma trial. For these reasons, patients with lymphoma may benefit substantially from adding adjuvant manganese porphyrin to chemotherapy protocols given its chemosensitization properties against lymphoma cells $[11,12]$. The high lymph node drug level is also an important finding when considering other types of cancers which metastasize to lymph nodes; for these cancers, improved treatment outcomes may also arise from adjuvant $\mathrm{MnBuOE}$.

The greatest obstacle in treating both human and canine lymphoma is the development of drug resistance. Treatment with adjuvant $\mathrm{MnBuOE}$ may be a way around this drug resistance. The combination of manganese porphryins and certain chemotherapy agents creates an environment of high oxidative stress within tumor cells. This pro-oxidant mechanism of chemosensitization by manganese porphyrins creates a scenario whereby lymphoma cells will be less likely to survive and develop drug resistance [11, 12]. This could lead to lengthened remission duration. Yet another advantage to performing comparative oncology studies in dogs is the ability to initiate a Phase I clinical trial prior to patients receiving and failing standard-of-care treatment protocols due to drug resistance. Given that phase I human lymphoma clinical trials typically are only able to evaluate treatment outcomes for patients who have already failed frontline therapy, reports of improved clinical outcomes for dogs treated upfront with experimental therapies, such as adjuvant $\mathrm{MnBuOE}$, could provide support for moving forward with subsequent human clinical trials.

Although there is more flexibility in performing a comparative oncology trial, it is imperative that the canine patients are treated safely and responsibly; after all, these dogs are companion animals. Therefore, before testing
$\mathrm{MnBuOE}$ in canine cancer patients, it was necessary to understand the safety and optimal dosing regimen in normal dogs. Prior studies in mice demonstrated pharmacological effects in tumor and normal tissues with $1 \mathrm{mg} / \mathrm{kg}$ subcutaneous administration of $\mathrm{MnBuOE}$ [5, 6, 22]. This dose is well below the MTD established for mice and nonhuman primates [21, 23]. Thus, $1 \mathrm{mg} / \mathrm{kg}$ was selected as a safe initial dose for MTD and single-dose PK studies in dogs which would also provide accurate measurement of $\mathrm{MnBuOE}$ in plasma even 14 days after injection. However, the $1 \mathrm{mg} / \mathrm{kg}$ dose of $\mathrm{MnBuOE}$ induced an anaphylactic drug reaction and a severe, prolonged tachycardia in the dogs. The acute drug reaction was prevented with premedications (steroids, anti-histamines) and the tachycardia was alleviated by reducing the $\mathrm{MnBuOE}$ dose. Neither intravenous fluid therapy nor anti-histamine medication affected the tachycardia, indicating that this toxicity is most likely a primary tachycardia and not secondary to hypotension. Consequently, the MTD was lowered to $0.25 \mathrm{mg} / \mathrm{kg}$. Aside from a mild to moderately increased heart rate $1 \mathrm{~h}$ postinjection that increased in severity over time, the dogs had no clinical evidence of toxicity throughout the multi-dose PK study at this dose. This change in heart rate throughout the multi-dose PK study is most likely due to accumulation of $\mathrm{MnBuOE}$ in the cardiac tissue. The acute anaphylactic drug reaction and tachycardia post-injection have not been described in other species and may be specific to canines.

Laboratory tests performed throughout the studies identified changes to the organ systems functions of the dogs when treated with MnBuOE. Following treatment of $\mathrm{MnBuOE}$ as single doses of 1 and $0.25 \mathrm{mg} / \mathrm{kg}$, as well as prolonged treatment in the first multi-dose study, alkaline urine was documented $(n=1-2 / 3)$. A slight-to-mild high anion gap metabolic acidosis developed in all three dogs following the 3-week multi-dose PK study. These results combined are indicative of renal damage. One dog developed a urinary tract infection during the study; however, this was most likely secondary to introduction of bacteria into the bladder during urine collection via cystocentesis. To prevent the anaphylactic drug reaction associated with $\mathrm{MnBuOE}$ administration, dogs were treated with prednisone and antihistamine medications throughout the multidose PK study. Prednisone can induce changes in liver enzyme activity, and, in fact, mildly increased liver enzyme levels were recorded in the three dogs; however, mild hypocholesterolemia was also found in the three $\operatorname{dog}$ s, which may indicate that the changes in the liver are due to damage from the MnBuOE.

Histopathologic evaluation of tissues revealed mild to moderate inflammatory and degenerative changes in the kidney, liver, and lungs. Consistent with the laboratory results, acute, mild to moderate tubular degeneration and necrosis of the kidney was reported $(n=3 / 3)$, as well 
as marked hydropic degeneration of the liver $(n=3 / 3)$. Interestingly, mild to moderate sterile bronchointerstitial/ interstitial pneumonia was discovered $(n=3 / 3)$. While $\mathrm{MnBuOE}$ causing these changes in the lungs cannot be ruled out, the characteristics of this pneumonia could also point to an acute injury from inhalation of a noxious cleaning agent from the kennel in which they were housed. Finally, mild necrosupporative/granulomatous inflammation was found in the subcutaneous adipose tissue of the injection site $(n=3 / 3)$. These findings have not been reported in other species and may be specific to canines.

Again, because manganese porphyrin compounds accumulate in primary tumors and lymph nodes, it may be possible to reduce the treatment dose and/or frequency of administration of $\mathrm{MnBuOE}$ for a canine lymphoma trial while maintaining clinical efficacy in order to reduce or prevent the identified toxicities.

\section{Compliance with ethical standards}

Funding This work was funded by a Grant from the Comparative Medicine Institute of North Carolina State University. Dr. Ivan Spasojevic is grateful for the support of NIH Core Grant, 5-P30-CA14236-29. Romulo S. Sampaio acknowledges the Brazilian Research Councils of the Coordination for the Improvement of Higher Education Personnel (CAPES) Foundation and the National Council for Scientific and Technological Development $(\mathrm{CNPq})$ to support his stay in Dr. Spasojevic's and Dr. Batinic-Haberle's Laboratories.

Conflict of interest Dr. Batinic-Haberle and Dr. Spasojevic are the inventors of MnBuOE. Drs. Batinic-Haberle, Spasojevic, and Dewhirst have received funding for prior work from BioMimetix JVLLC. Dr. Batinic-Haberle, Dr. Spasojevic, and Duke University have patent rights and have licensed technologies to BioMimetix JVLLC. Dr. Batinic-Haberle and Dr. Spasojevic are consultants with BioMimetix JVLLC and hold equities in BioMimetix JVLLC.

Ethical approval All animal care and experimental procedures were approved by and complied with the regulations of the North Carolina State University Institutional Animal Care and Use Committee. This article does not contain any studies with human participants performed by any of the authors.

Open Access This article is distributed under the terms of the Creative Commons Attribution 4.0 International License (http:// creativecommons.org/licenses/by/4.0/), which permits unrestricted use, distribution, and reproduction in any medium, provided you give appropriate credit to the original author(s) and the source, provide a link to the Creative Commons license, and indicate if changes were made.

\section{References}

1. Moeller BJ, Cao YT, Li CY, Dewhirst MW (2004) Radiation activates HIF-1 to regulate vascular radiosensitivity in tumors: role of reoxygenation, free radicals, and stress granules. Cancer Cell 5(5):429-441. doi:10.1016/s1535-6108(04)00115-1
2. Il'yasova D, Kennedy K, Spasojevic I, Wang F, Tolun AA, Base K, Young SP, Marcom PK, Marks J, Millington DS, Dewhirst MW (2011) Individual responses to chemotherapy-induced oxidative stress. Breast Cancer Res Treat 125(2):583-589. doi:10.1007/s10549-010-1158-7

3. Chirino YI, Pedraza-Chaverri J (2009) Role of oxidative and nitrosative stress in cisplatin-induced nephrotoxicity. Exp Toxicol Pathol 61(3):223-242. doi:10.1016/j.etp.2008.09.003

4. Aird KM, Allensworth JL, Batinic-Haberle I, Lyerly HK, Dewhirst MW, Devi GR (2012) ErbB1/2 tyrosine kinase inhibitor mediates oxidative stress-induced apoptosis in inflammatory breast cancer cells. Breast Cancer Res Treat 132(1):109-119. doi:10.1007/s 10549-011-1568-1

5. Ashcraft KA, Boss MK, Tovmasyan A, Roy Choudhury K, Fontanella AN, Young KH, Palmer GM, Birer SR, Landon CD, Park W, Das SK, Weitner T, Sheng H, Warner DS, Brizel DM, Spasojevic I, Batinic-Haberle I, Dewhirst MW (2015) Novel manganese-porphyrin superoxide dismutase-mimetic widens the therapeutic margin in a preclinical head and neck cancer model. Int J Radiat Oncol Biol Phys 93(4):892-900. doi:10.1016/j. ijrobp.2015.07.2283

6. Weitzel DH, Tovmasyan A, Ashcraft KA, Rajic Z, Weitner T, Liu C, Li W, Buckley AF, Prasad MR, Young KH, Rodriguiz RM, Wetsel WC, Peters KB, Spasojevic I, Herndon JE, BatinicHaberle I, Dewhirst MW (2015) Radioprotection of the brain white matter by $\mathrm{Mn}$ (III) $N$-Butoxyethylpyridylporphyrin-Based superoxide dismutase mimic MnTnBuOE-2-PyP5+. Mol Cancer Ther 14(1):70-79. doi:10.1158/1535-7163.mct-14-0343

7. Gauter-Fleckenstein B, Fleckenstein K, Owzar K, Jiang C, Rebouças JS, Batinic-Haberle I, Vujaskovic Z (2010) Early and late administration of MnTE-2-PyP5+ in mitigation and treatment of radiation-induced lung damage. Free Radical Biol Med 48(8):1034-1043. doi:10.1016/j.freeradbiomed.2010.01.020

8. Gauter-Fleckenstein B, Fleckenstein K, Owzar K, Jiang C, Batinic-Haberle I, Vujaskovic Z (2008) Comparison of two Mn porphyrin-based mimics of superoxide dismutase in pulmonary radioprotection. Free Radical Biol Med 44(6):982-989. doi:10.1016/j.freeradbiomed.2007.10.058

9. Moeller BJ, Batinic-Haberle I, Spasojevic I, Rabbani ZN, Anscher MS, Vujaskovic Z, Dewhirst MW (2005) A manganese porphyrin superoxide dismutase mimetic enhances tumor radioresponsiveness. Int J Radiat Oncol Biol Phys 63(2):545-552. doi:10.1016/j.ijrobp.2005.05.026

10. Batinic-Haberle I, Tovmasyan A, Roberts ERH, Vujaskovic Z, Leong KW, Spasojevic I (2014) SOD therapeutics: latest insights into their structure-activity relationships and impact on the cellular redox-based signaling pathways. Antioxid Redox Signal 20(15):2372-2415. doi:10.1089/ars.2012.5147

11. Jaramillo MC, Frye JB, Crapo JD, Briehl MM, Tome ME (2009) Increased manganese superoxide dismutase expression or treatment with manganese porphyrin potentiates dexamethasoneinduced apoptosis in lymphoma cells. Can Res 69(13):5450 5457. doi:10.1158/0008-5472.can-08-4031

12. Jaramillo MC, Briehl MM, Batinic-Haberle I, Tome ME (2015) Manganese (III) meso-tetrakis N-ethylpyridinium-2-yl porphyrin acts as a pro-oxidant to inhibit electron transport chain proteins, modulate bioenergetics, and enhance the response to chemotherapy in lymphoma cells. Free Radical Biol Med 83:89-100. doi:10.1016/j.freeradbiomed.2015.01.031

13. Hernandez-Ilizaliturri FJ, Reddy N, Holkova B, Ottman E, Czuczman MS (2005) Immunomodulatory drug CC-5013 or CC-4047 and rituximab enhance antitumor activity in a severe combined immunodeficient mouse lymphoma model. Clin Cancer Res 11(16):5984-5992. doi:10.1158/1078-0432.ccr-05-0577

14. Bric A, Miething C, Bialucha CU, Scuoppo C, Zender L, Krasnitz A, Xuan ZY, Zuber J, Wigler M, Hicks J, McCombie RW, 
Hemann MT, Hannon GJ, Powers S, Lowe SW (2009) Functional identification of tumor-suppressor genes through an in vivo RNA interference screen in a mouse lymphoma model. Cancer Cell 16(4):324-335. doi:10.1016/j.ccr.2009.08.015

15. LeBlanc AK, Breen M, Choyke P, Dewhirst M, Fan TM, Gustafson DL, Helman LJ, Kastan MB, Knapp DW, Levin WJ (2016) Perspectives from man's best friend: National Academy of Medicine's Workshop on Comparative Oncology. Sci Trans Med 8(324):324-325

16. Vail DM, MacEwen EG (2000) Spontaneously occurring tumors of companion animals as models for human cancer. Cancer Invest 18(8):781-792. doi:10.3109/07357900009012210

17. Richards KL, Motsinger-Reif AA, Chen HW, Fedoriw Y, Fan C, Nielsen DM, Small GW, Thomas R, Smith C, Dave SS, Perou CM, Breen M, Borst LB, Suter SE (2013) Gene profiling of canine B-cell lymphoma reveals germinal center and postgerminal center subtypes with different survival times, Modeling Human DLBCL. Cancer Res 73(16):5029-5039. doi:10.1158/0008-5472.can-12-3546

18. Richards KL, Suter SE (2015) Man's best friend: what can pet dogs teach us about non-Hodgkin's lymphoma? Immunol Rev 263(1):173-191. doi:10.1111/imr.12238

19. Rajic Z, Tovmasyan A, Spasojevic I, Sheng HX, Lu MM, Li AM, Gralla EB, Warner DS, Benov L, Batinic-Haberle I (2012) A new SOD mimic, Mn(III) ortho N-butoxyethylpyridylporphyrin, combines superb potency and lipophilicity with low toxicity. Free Radical Biol Med 52(9):1828-1834. doi:10.1016/j. freeradbiomed.2012.02.006

20. Tovmasyan A, Carballal S, Ghazaryan R, Melikyan L, Weitner T, Maia CGC, Reboucas JS, Radi R, Spasojevic I, Benov L, Batinic-Haberle I (2014) Rational design of superoxide dismutase (SOD) mimics: the evaluation of the therapeutic potential of new cationic Mn porphyrins with linear and cyclic substituents. Inorg Chem 53(21):11467-11483. doi:10.1021/ ic501329p

21. Gad SC, Sullivan DW Jr, Spasojevic I, Mujer CV, Spainhour CB, Crapo JD (2016) Nonclinical Safety and Toxicokinetics of MnTnBuOE-2-PyP5+ (BMX-001). Int J Toxicol. doi: $10.1177 / 1091581816642766$

22. Tovmasyan A, Sampaio RS, Boss MK, Bueno-Janice JC, Bader BH, Thomas M, Reboucas JS, Orr M, Chandler JD, Go YM, Jones DP, Venkatraman TN, Haberle S, Kyui N, Lascola CD, Dewhirst MW, Spasojevic I, Benov L, Batinic-Haberle I (2015) Anticancer therapeutic potential of $\mathrm{Mn}$ porphyrin/ascorbate system. Free Radic Biol Med 89:1231-1247. doi:10.1016/j. freeradbiomed.2015.10.416

23. Batinic-Haberle I, Tovmasyan A, Spasojevic I (2016) Mn porphyrin-based redox-active therapeutics. In Redox-Active Therapeutics. Springer International Publishing, Switzerland. doi:10.1007/978-3-319-30705-3_8

24. Batinic-Haberle I, Spasojevic I, Tse HM, Tovmasyan A, Rajic Z, St Clair DK, Vujaskovic Z, Dewhirst MW, Piganelli JD (2012) Design of Mn porphyrins for treating oxidative stress injuries and their redox-based regulation of cellular transcriptional activities. Amino Acids 42(1):95-113. doi:10.1007/s00726-010-0603-6

25. Platt R, Ng T, Glover S, Roof M, Kimura K, Roth JA (2013) Canine peripheral blood lymphocyte phenotyping by 7-color multiparameter flow cytometry. Anal Quant Cytol Histol 35(4):197-204 